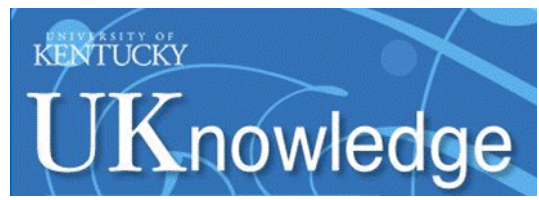

University of Kentucky

UKnowledge

Biosystems and Agricultural Engineering Faculty Publications

\title{
$5-2016$
}

\section{Mobile Device-Based Location Services Accuracy}

\author{
Hasan Seyyedhasani \\ University of Kentucky, hshasanit@uky.edu \\ Joseph S. Dvorak \\ University of Kentucky, joe.dvorak@uky.edu \\ Michael P. Sama \\ University of Kentucky, michael.sama@uky.edu \\ Tim S. Stombaugh \\ University of Kentucky, tim.stombaugh@uky.edu
}

Follow this and additional works at: https://uknowledge.uky.edu/bae_facpub

Part of the Bioresource and Agricultural Engineering Commons

Right click to open a feedback form in a new tab to let us know how this document benefits you.

\section{Repository Citation}

Seyyedhasani, Hasan; Dvorak, Joseph S.; Sama, Michael P.; and Stombaugh, Tim S., "Mobile Device-Based Location Services Accuracy" (2016). Biosystems and Agricultural Engineering Faculty Publications. 16. https://uknowledge.uky.edu/bae_facpub/16

This Article is brought to you for free and open access by the Biosystems and Agricultural Engineering at UKnowledge. It has been accepted for inclusion in Biosystems and Agricultural Engineering Faculty Publications by an authorized administrator of UKnowledge. For more information, please contact UKnowledge@lsv.uky.edu. 


\section{Mobile Device-Based Location Services Accuracy}

Digital Object Identifier (DOI)

https://doi.org/10.13031/aea.32.11351

Notes/Citation Information

Published in Applied Engineering in Agriculture, v. 32, no. 5, p. 539-547.

() 2016 American Society of Agricultural and Biological Engineers

The copyright holder has granted the permission for posting the article here. 


\title{
TECHNICAL NOTE:
}

\section{MOBILE DEVICE-BASED LOCATION SERVICES ACCURACY}

\author{
H. Seyyedhasani, J. S. Dvorak, M. P. Sama, T. S. Stombaugh
}

\begin{abstract}
The objective of this study was to characterize the expected position accuracy when using popular mobile devices for location-based agricultural decision-making activities. This study utilized Android-based Nexus 7 tablets and tested the operation of the three location services available on this system in a 24-h fixed location test and a shorter duration multiple location field test. In the 24- $h$ test, the "network" location system had a measured error of $37.19 \mathrm{~m}$ while reporting an accuracy of $55.56 \mathrm{~m}$. The "gps" location system had a measured error of $2.57 \mathrm{~m}$ and a reported accuracy of $3.20 \mathrm{~m}$. Multiple tests were conducted with the location system added by Google Services code because the measured error was much higher than the reported accuracy. With this system, the measured errors were 14.13, 3.4, 24.08, 14.01, and $16.15 \mathrm{~m}$ with reported accuracies of 3.95, 4.83, 3.99, 7.18, and $6.68 \mathrm{~m}$, respectively. All the tests with the Google Services location system had much higher variability in location estimates than the "gps" location system. For both services, the high values for reported accuracy did not correspond with high values for measured error. Field testing was only performed with the Google Services and "gps" location systems as the "network" location system did not operate in the test field. Statistical analysis confirmed that the "gps" system was more accurate in this testing but the difference was not as dramatic as in the 24-h testing. The average reported accuracy level was $3.0 \mathrm{~m}$ in all field tests with the "gps" system and $3.9 \mathrm{~m}$ in all field tests with the Google Services system. The field test data were also used to estimate areas of 0.14-ha rectangular plots. Among all three tests with the "gps" system and all three tests with the Google Services system, the mean absolute area percent error varied from $4 \%$ to $7 \%$, and in every test at least one plot was over-or underestimated by at least $10 \%$. The error characteristics and patterns for all but the "gps" service differed significantly from the random walk pattern and/or other characteristics of GNSS locators to which precision farming engineers have become accustomed. Mobile platform creators like Apple and Google are either requiring (Apple) or strongly encouraging (Google) developers to switch to newer services that don't provide access to the underlying locating mechanism. Therefore, it is clear that careful consideration of these differences and what they may mean to location based apps in agriculture will be important. This work highlights the importance of testing any "smart" devices to determine actual location accuracy before relying on them for making agricultural decisions based on their output.
\end{abstract}

Keywords. Accuracy, Android, Global navigation satellite system, Location, Smartphone.

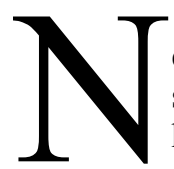

early half of all American farmers used a smartphone in 2012 (Doering, 2013). Many apps have been specifically created to help improve

Submitted for review in May 2015 as manuscript number ITSC 11351; approved as a Technical Note for publication by the Information, Technology, Sensors, \& Control Systems Community of ASABE in May 2016.

Publication No. 16-05-085 of the Kentucky Agricultural Experiment Station, published with the approval of the Director.

The authors are Hasan Seyyedhasani, ASABE Member, Graduate Student, Joseph S. Dvorak, ASABE Member, Assistant Professor, Michael P. Sama, ASABE Member, Assistant Professor, Tim S. Stombaugh, ASABE Member, Professor, Department of Biosystems and Agricultural Engineering, University of Kentucky, Lexington, Kentucky. Corresponding author: Hasan Seyyedhasani, Department of Biosystems and Agricultural Engineering, University of Kentucky, 128 C.E. Barnhart Building, Lexington, KY 40546-0276; phone: 859-257-3000; e-mail hshasaniT@uky.edu. productivity in agricultural operations. Researchers have described the general use of apps for Extension ( Guenthner and Swan, 2011; Drill, 2012) and other projects have focused on specific apps to solve challenging Extension issues (McCullough, Jr. et al., 2011; Dvorak et al., 2012). Recently, the Open Ag Toolkit project has produced apps that utilize cloud-based systems to provide a more producer-focused Farm Management Information System (Welte et al., 2013a; 2013b).

Many apps developed for use by farmers utilize the location services of these devices for part of their operation. This includes apps such as Insect Resistance Management Refuge Calculator by the National Corn Growers Association (2013), Mix Tank by Precision Laboraties (2014), Pioneer Field360 by Dupont Pioneer (2013), and SoilWeb by Beaudette (2011). Connected Farm Scout by Trimble Navigation (2014) allows producers to record location- 
based scouting information like NDVI readings, weed locations, field boundaries, or mark other areas of interest. The Open Ag Toolkit project has produced the Field Work Open ATK (Open Ag ToolKit, 2014a) app for recording field work and the Rock - OpenATK (Open Ag ToolKit, 2014b) app for recording rock locations in fields. The Watershed Management Apps Center produced the Water Plane - WMAC (Watershed Management Apps Center, 2014) app for visualizing ground elevations and the Watershed Delineation - WMAC (Watershed Management Apps Center, 2013) app for visualizing watersheds. All of these OpenATK and Watershed Management Apps Center apps use the device's location sensors in their operation. Engineers and others serving the agricultural industry have realized that the computational power, sensors and portability of these devices can be used to improve agricultural productivity. However, the location-based services available on these devices do not perform in the same manner as those that have traditionally powered precision agriculture. Nearly every device has methods in addition to a Global Navigation Satellite System (GNSS) for determining location. These depend on the device, but generally include systems that rely on signal strengths of wireless systems like $\mathrm{Wi}-\mathrm{Fi}$ access points or wireless-carrier towers. All of these location sensors are embedded within a larger System on a Chip (SoC) that runs most critical processes for the device. Since the hardware for all these location services are combined and embedded within a much larger SoC and the controlling software is embedded within the mobile operating system, there is very little information on the details of the location services as they are just small parts of a much larger product. For these reasons, it is important to investigate the operation of these systems so that engineers developing applications for these types of devices can have a better idea of what to expect.

The Android system produced by Google includes three locations services which the Android documentation titles "network," "gps," and "fused." The "network" service is based on the wireless networks detected by the device, and the "gps" service relies on satellites. The "fused" service is Google's preferred method for adding location awareness to an Android app and is provided by Google Services for the Android system. On its Android development web site, Google instructs developers that they "are strongly encouraged to switch to [the "fused" service]" (Google, 2015b). There is little information on the operation of this Google Services location service, and it is essentially presented to the application developer as black box. Based on the testing in this project, the Google Services locator appeared to combine information from both the "network" and the "gps" locating services but the method for this combination was not clear. All three services provided the application with an estimate of latitude and longitude and an accuracy value as part of each location measurement. This accuracy provided by the location services was defined within the Android documentation such that the distance between the true location and the reported location should be less than this many meters $68 \%$ of the time (Google, 2015a). The "gps" service also provided information on the available satellites that had been detected and used in the location determination.
iOS devices similarly provide developers with location services; however, developers are limited to using only one service which comes from iOS's Core Location framework (Apple, 2015c). The developer is able to request various levels of accuracy from three kilometers to a highest possible accuracy (Apple, 2015b), but all decisions relating to how that location is determined are made by the iOS device (Apple, 2015c). Like Android's location services, iOS's Core Location framework provides location estimates that include both estimates of latitude and longitude and an accuracy value, but there is no information on what device hardware was used to provide the result or satellites available (Apple, 2015a). The iOS accuracy value is, like the Android value, provided in meters, but unlike Android, the iOS documentation does not provide a statistical benchmark (i.e., $\mathrm{X} \%$ of values are expected within this distance) (Apple, 2015a).

The objective of this study was to compare the characteristics and abilities of the variety of different location services available on these mobile devices for applicability in agricultural uses. Testing involved experiments with the different location sensors on a device. One set of tests conformed to an established standard procedure to compare location accuracy between different locating services and to determine if the device's self-reported accuracy was correct. A second set of tests focused on a use case more likely to reflect actual use of such a device in a field setting for making agricultural decisions. This testing was specifically not designed to be a benchmark test of location service implementations in various manufacturers' devices. Expected accuracies for a particular implementation depend on the SoC used, the IP for the location circuitry in that $\mathrm{SoC}$, the antenna and device hardware design, the mobile operating system and patches to the operating system applied by mobile network operators for various reasons. Within the mobile device market, these factors are constantly changing so benchmarking seems a better fit for commercial entities. Rather than providing specific accuracy values for specific devices, this project focused on the characteristics of these location services and especially how they differ.

For basic GNSS devices, there has been considerable research and standards development to properly describe and evaluate the effects of differing operating modes like WAAS and RTK. The basic operating characteristics of GNSS locating devices have led to the development of terms like pass-to-pass accuracy or position drift. However, the authors are not aware of any similar research to describe the alternative locating services as they are utilized in modern mobile devices for agricultural applications. Engineers developing apps for these mobile device systems will need to carefully consider the general characteristics and error patterns as they are not similar to the standard GNSS location services often used in precision agriculture. The overall goal of this project was to provide insight into the strengths, weaknesses, and possible issues involved with using these types of devices for location-based agricultural decision-making. 


\section{Methods ANd Materials \\ EQUIPMENT}

In this project, all testing was performed using the Android platform as it is the only major mobile platform to provide methods to directly access the underlying location subsystems. This testing also required a standard, stable implementation of the Android platform on which to perform the testing. Fortunately, Google created the Nexus line of devices to provide a standard Android experience on a base version of Android. Therefore, the 2013 Nexus 7 (ASUS, Taiwan), which uses Qualcomm's (San Diego, Calif.) APQ8064 SoC and IZat Gen 8A location technology (Qualcomm Technologies, 2014), was chosen as the test platform. The Nexus 7 tablet system was purchased without cellular connectivity to eliminate any effects dependent on wireless service providers. Two tablets were used during testing. One was running Android 4.4.2 and the other Android 4.4.3. Android provides all three location services on the Nexus 7: "network," "gps," and one provided by Google Services.

A custom Android program was developed which allowed selection and configuration of the location service and logging of data. Available Android applications do not provide access to the underlying configuration of the location services and are not capable of operating and recording data in the manner required for testing to the standard used in this project. This custom application configured the location services on the tablet to provide location data as soon as a new location was resolved. From this location data, the estimate of latitude and longitude and the accuracy value of each location measurement as reported by the location service was then immediately recorded to a file for post-processing. This accuracy value will henceforth be referred to as self-reported accuracy or SRA to distinguish it from accuracy values determined through this testing. The application also had to disable power saving and sleep functions on the tablet for the extended duration testing.

\section{Institute of Navigation 101 Testing}

The first set of tests in this project was designed to determine the accuracy of the various locating services and how these accuracy levels compared to the SRA. This testing followed the procedures given in the Institute of Navigation (ION) legacy Standard 101 which requires 24-h recording of location data with a stationary device at a known location (The Institude of Navigation, 1997). A Trimble NetR8 GNSS Reference Receiver (Trimble, Sunnyvale, Calif.) was used to survey the locations of the mounting points located on the University of Kentucky campus that were used to hold the device stationary. The mounting points were surveyed to enable them to serve as benchmarks in the static testing. The NetR8 was capable of storing raw GNSS data needed to determine an accurate position using post-processing techniques. The NetR8's raw data were recorded for 24 hours, and then converted to Receiver Independent Exchange Format (RINEX) using Trimble's Convert-to-Rinex utility. Post-processing was performed using the Online Positioning User Service (OPUS) with data from the Kentucky Transportation Cabinet's Continuously Operated Reference Stations (CORS) network. This resulted in surveyed coordinates for each mounting point with a maximum Northing or Easting error of $13 \mathrm{~mm}$ relative to the statewide CORS network. This maximum error for the mounting points was well within requirements of the ION Standard 101 for testing devices with an expected error greater than meter-level.

This testing was conducted once for each location service: "network," "gps," and Google Services. Because the first test with Google Services showed larger than expected error compared to the "gps" service, the Google Services test was repeated four more times, and two different Nexus 7 tablets were used. The data were processed according to the procedures in section 6.5 of ION 101 to calculate horizontal predictable accuracy ( $\triangle \mathrm{HPRE}$ ), which calls for the use of the following equations (1-4) from GPS NAVSTAR (1995). The easting and northing instantaneous errors were calculated as:

$$
\begin{aligned}
& \Delta \mathrm{e}(\mathrm{tk})= \\
& {[\lambda \text { measured }(\mathrm{tk})-\lambda \text { site }] 111319.4908 \mathrm{cos} \phi \text { site }} \\
& \Delta n\left(t_{k}\right)=\left[\phi_{\text {measured }}\left(t_{k}\right)-\phi_{\text {site }}\right] 111319.4908
\end{aligned}
$$

where

$\lambda_{\text {site }}$ is the precise longitude of the intended spot $\left(^{\circ}\right)$,

$\lambda_{\text {measured }}$ is the measured longitude of the intended spot $\left(^{\circ}\right)$,

$\phi_{\text {site }}$ is the precise latitude of the intended spot $\left({ }^{\circ}\right)$,

$\phi_{\text {measured }}$ is the measured latitude of the intended spot $\left(^{\circ}\right)$,

$t_{k}$ is the time (s),

$\Delta e\left(t_{k}\right)$ and $\Delta n\left(t_{k}\right)$ are the east and north instantaneous errors $(\mathrm{m})$, respectively, and,

111319.4908 is the constant provided by GPS NAVSTAR (1995) and converts degrees to meters.

The instantaneous (measured) horizontal accuracy error, $\Delta \mathrm{H}\left(t_{k}\right)$, in meters, was calculated as:

$$
\Delta \mathrm{H}(\mathrm{tk})=\left[(\Delta \mathrm{e}(\mathrm{tk})) 2+(\Delta \mathrm{n}(\mathrm{tk}))^{2}\right]^{1 / 2}
$$

The $\Delta H$ values were then ordered and the values at different percentiles were calculated.

The $\triangle$ HPRE for the $68^{\text {th }}$ percentile, $\triangle \mathrm{HPRE}_{68}$, was of particular interest since based on Android's definition of SRA and the ION 101's definition for $\triangle \mathrm{HPRE}$, these values should correspond with each other. $\triangle \mathrm{HPRE}_{68}$, in meters, was calculated as (GPS NAVSTAR, 1995):

$$
\begin{gathered}
\Delta \text { HPRE68 }=\Delta \mathrm{H} \text { value at } n ; \\
\text { for } n=\operatorname{Integer}\left(0.68 \times \mathrm{S}_{\mathrm{ACC}}\right)
\end{gathered}
$$

where

$n$ is number of the sample associated with the 68th percentile, and

$\mathrm{S}_{\mathrm{ACC}}$ equals the number of samples over the measurement interval.

\section{Field Testing}

The second set of tests in this project were conducted in a field using procedures closer to a use case for these systems in agricultural decision-making. It is assumed that many agriculture producers who use the location abilities of these mobile systems for work will be using them to mark points in a field. These points could correspond to rock or hazard 
locations, weed locations, soil sample locations, the corners of a weedy area to be marked for spraying, the corners of areas planted to different crops or different varieties, or marking the locations of sensitive plants for determination of spray buffer zones. In all of these cases, producers would carry the device to the point and then stop at the point to record it. This testing was performed at the University of Kentucky Horticulture Research Farm in Lexington, Kentucky. The area utilized in this testing was part of an organic Community Supported Agriculture (CSA) project and had been divided into approximately 0.14 -ha plots for various vegetables. The field test simulated the marking of points in a field by using the devices to determine the locations of 88 points which were located around the edges of vegetable production plots. The locations of these points were previously established using a Trimble 5800 GPS System (Trimble, Sunnyvale, Calif.) operating in RTK mode with internetbased corrections provided by the Kentucky Transportation Cabinet CORS network. At each point, the location data provided to the application by the location service were recorded for two minutes. More than a single sample from one second was required to provide enough samples to permit the calculation of $\triangle \mathrm{HPRE}_{68}$ for comparison with the tablet's SRA, and 2 minutes approximates the time that might be spent in a single location during field scouting. This field testing was conducted with the "gps" and Google Services locating services with three repetitions for each. The "network" location service would not operate at this location so it was not utilized for the field test.

\section{RESULTS AND DisCUSSIONS ION 101 TESTING}

Table 1 displays a comparison of location services based on the static testing. For the "network" and "gps" locator, the $\triangle$ HPRE $_{68}$ was lower than the average SRA implying that SRA levels were conservative estimates. The results from the tests with the Google Services locator did not follow this pattern. Instead, the $\triangle \mathrm{HPRE}_{68}$ for Google Services measured lower than average SRA and the error levels were higher than expected. Based on the Android documentation and Google's strong recommendation to use this service, it had been expected to be as good if not better than the regular "gps" locator. However, in four of the five Google Services locator tests, the $\triangle \mathrm{HPRE}_{68}$ was more than five times larger than that from the "gps" locator and the $\triangle \mathrm{HPRE}_{68}$ was much larger than the average SRA. In the worst case, the calculated $\triangle \mathrm{HPRE}_{68}$ was over $500 \%$ larger than the average SRA. The large location errors were noticed with both tablets, so this behavior was not related to defective hardware. While the Google Services locator was not the most accurate and provided misleading SRA, it did produce the largest number of valid samples in $24 \mathrm{~h}$ which might be important in applications where an unreliable accuracy level can be traded for availability.

As demonstrated in table 1, in addition to having the lowest $\triangle \mathrm{HPRE}_{68}(2.57 \mathrm{~m})$ and mean error $(2.16 \mathrm{~m})$, the test with the "gps" locator also had the least amount of variability in its error (standard deviation of $0.59 \mathrm{~m}$ ). The standard deviations of the tests with the Google Services locator were all at least seven times larger (standard deviations from 4.30 to $7.45 \mathrm{~m}$ ). A Tukey HSD test for unequal group sizes concluded that each test run represented its own unique subset. For all comparisons between groups, the significance was less than 0.001 . Although unsurprising in tests with different services, it was surprising that repeated tests with Google Services were not similar.

To understand the errors for the various services, figure 1, which shows the northing and easting errors, was developed. The "gps" (fig. 1a) and Google Services (fig. 1b) locators produced the random walk pattern typically associated with GNSS systems. Also, with these locators some inaccurate sampling initially occurred and then errors concentrated in a smaller region. In the case of Google Services (fig. 1b), this concentrated smaller region was offset from the true location in a different direction with each test run. Unlike the "gps" and Google Services locators, successive location estimates from the "network" locator were not close to each other and jumped from one region to another (fig. 1c). The initial location estimates for "network" began immediately unlike "gps" which required a startup period. The first few samples of each test with the Google Services locator appeared to be based on the "network" locator as they were provided more quickly than those from the "gps" locator and their distribution matched that of the "network" locator.

ION 101 calls for the calculation of $\triangle \mathrm{HPRE}$ at multiple percentiles, but so far only $\triangle \mathrm{HPRE}_{68}$ has been presented as it allows for direct comparison with SRA. The $\triangle$ HPRE at different percentiles for the "gps" and the Google Services locator tests is presented in figure 2. For the "gps" location service, $\triangle$ HPRE is relatively constant from the $50^{\text {th }}$ to the $99^{\text {th }}$ percentile with only a slight increase from about 2 to $3.5 \mathrm{~m}$. On the other hand, there is a sharp increase in error for the tests with the Google Services locator at around $90 \%$. Even the best test with the Google Services locator, Google Services 2, exhibits this increase. Although the summary information presented in table 2 appears to show that the "gps"

Table 1. Comparison of $\triangle \mathrm{HPRE}_{68}$ and SRA for different location services.

\begin{tabular}{|c|c|c|c|c|c|c|c|}
\hline $\begin{array}{l}\text { Run } \\
\text { No. }\end{array}$ & Location System Used & Device & $\begin{array}{c}\Delta \mathrm{HPRE}_{68} \\
(\mathrm{~m})\end{array}$ & $\begin{array}{c}\text { Average } \\
\text { Self-Reported } \\
\text { Accuracy (SRA) } \\
(\mathrm{m})\end{array}$ & $\begin{array}{l}\text { Samples } \\
\text { Received } \\
\text { in } 24 \mathrm{~h}\end{array}$ & $\begin{array}{l}\text { Mean } \\
\text { Error }^{[\mathrm{a}]} \\
(\mathrm{m})\end{array}$ & $\begin{array}{l}\text { Std. Dev. } \\
\text { of Error }{ }^{[a]} \\
\quad(\mathrm{m})\end{array}$ \\
\hline 1 & "network" & Asus Nexus 7 Android 4.4.2 & 37.19 & 55.56 & 16,824 & 39.47 & 42.34 \\
\hline 2 & “gps” & Asus Nexus 7 Android 4.4.2 & 2.57 & 3.20 & 86,400 & 2.16 & 0.59 \\
\hline 3 & Google Services & Asus Nexus 7 Android 4.4.2 & 14.13 & 3.95 & 103,243 & 12.22 & 4.30 \\
\hline 4 & Google Services & Asus Nexus 7 Android 4.4.2 & 3.40 & 4.83 & 173,125 & 4.82 & 6.47 \\
\hline 5 & Google Services & Asus Nexus 7 Android 4.4.2 & 24.08 & 3.99 & 103,359 & 20.56 & 7.45 \\
\hline 6 & Google Services & Asus Nexus 7 Android 4.4.3 & 14.01 & 7.18 & 103,296 & 14.92 & 6.66 \\
\hline 7 & Google Services & Asus Nexus 7 Android 4.4.3 & 16.15 & 6.68 & 107,012 & 16.03 & 4.40 \\
\hline
\end{tabular}

[a] Error is the location error (distance between location estimate and the true location). 

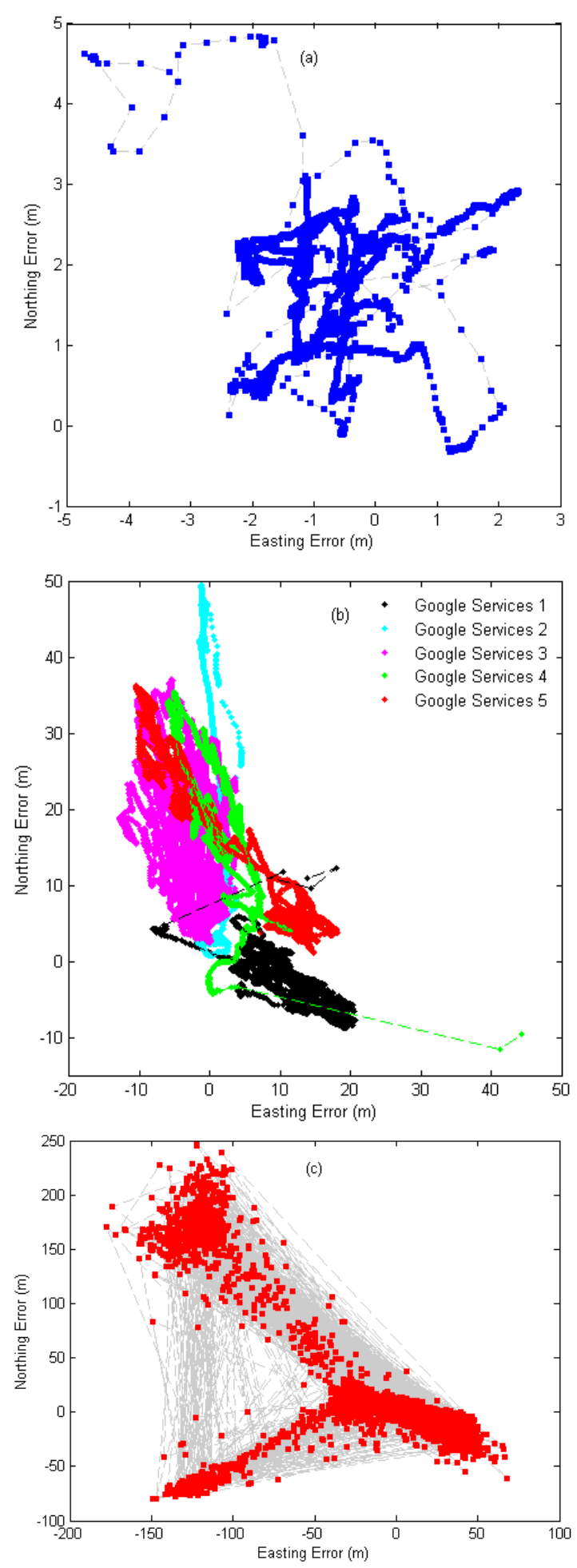

Figure 1. Northing and Easting errors for (a)"gps," (b) Google Services, and (c) "network" locators over $24 \mathrm{~h}$. The shapes represent the measured points, and the dashed lines connect successive measurements.

and the Google Services 2 test were very similar, the data in figure 2 demonstrate that Google Services 2 also had measurements with high error, but these were confined to the higher percentiles and so did not show up in $\triangle \mathrm{HPRE}_{68}$. This difference between error distributions of the Google Services tests and the "gps" test again reveals that the newer and

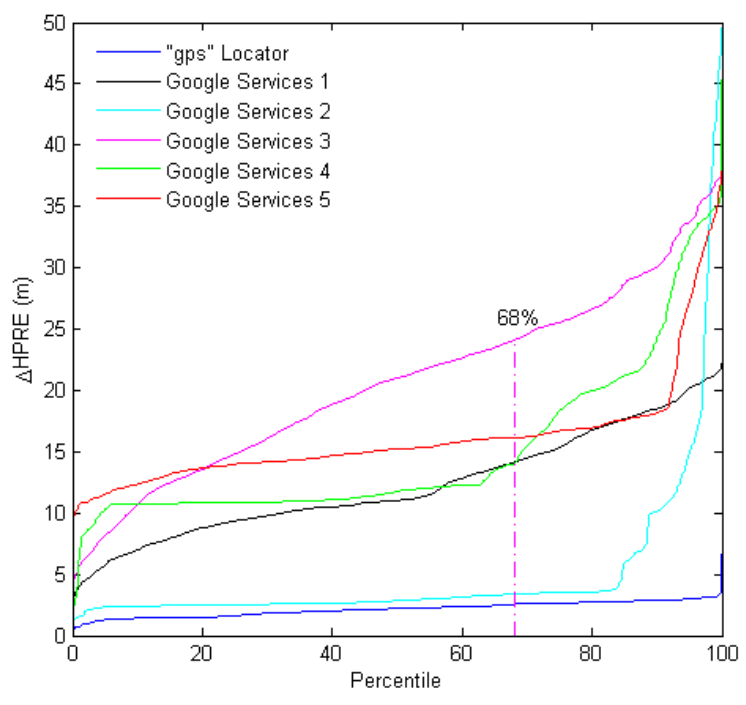

Figure 2. $\triangle$ HPRE at different percentiles for the "gps" and Google Services locators. A dashed line highlights the position of the $68^{\text {th }}$ percentile.

strongly suggested Google Services locator differs significantly from the traditional satellite-based "gps" locator.

It is also important to consider the distribution of SRA values that each location service provides. For engineers and programmers developing applications that rely on location services, the SRA is generally the only indication they will have of the operating status of the service. Instantaneous SRA over time is presented in figures 3, 4, and 5 for the "network," "gps," and Google Services locator, respectively. As shown, the "network" locator has considerable overall variability in SRA; however, most samples are concentrated between 25 and $80 \mathrm{~m}$. Figure 4 shows that the SRA during the test of the "gps" locator was at discrete values and was more consistent than the continuously varying "network" locator SRA. The SRA for the "gps" locator generally held at a constant value with occasional increases. The SRAs for the Google Services locator tests also occurred at discrete values (fig. 5) and exhibited a pattern similar to that of the "gps" locator with brief periods of SRA above the normal constant value.

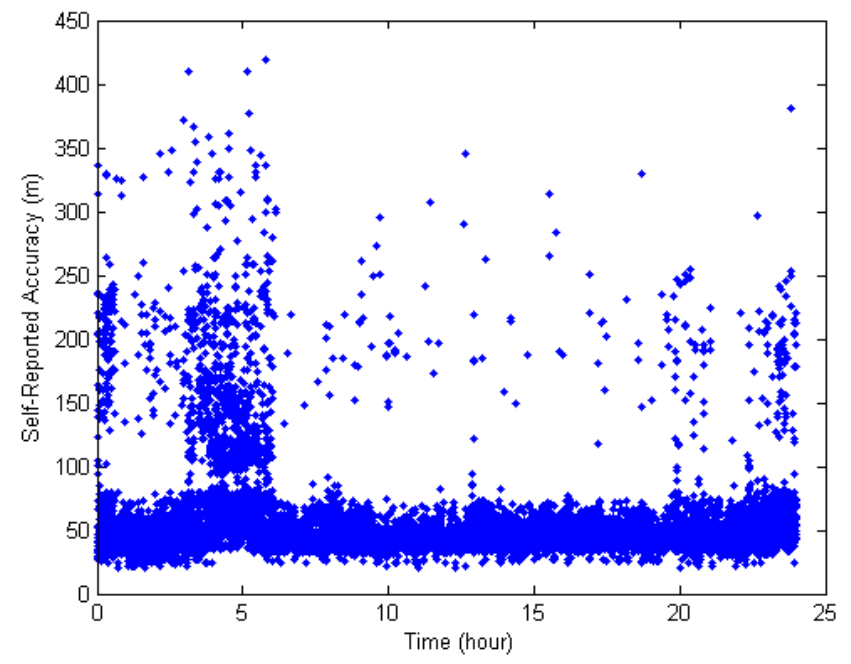

Figure 3. Self-Reported Accuracy of the "network" locator over the 24-h test period. 


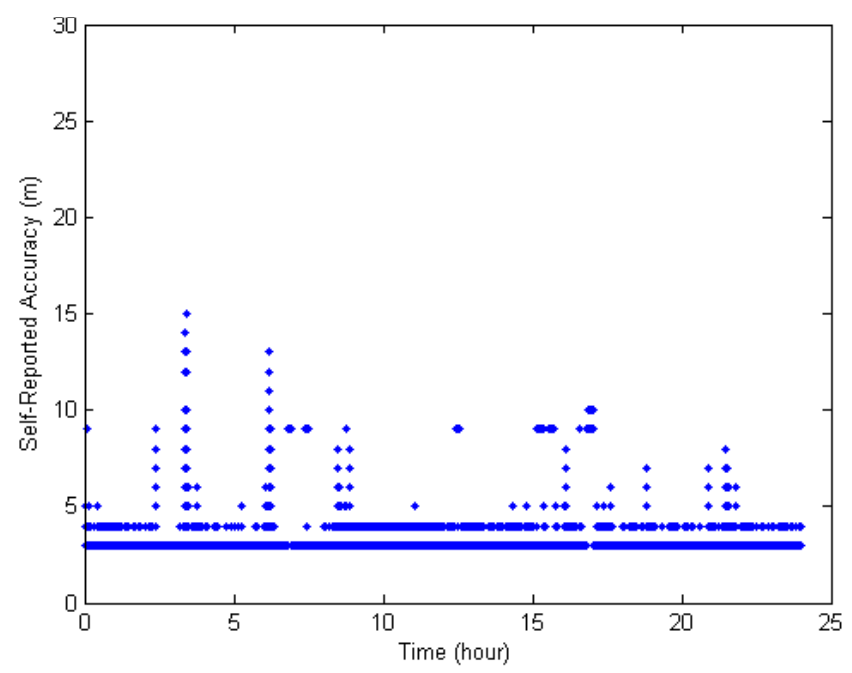

Figure 4. Self-Reported Accuracy of the "gps" locator over the 24-h test period.

\section{Field Testing}

The results obtained in this part of the testing were focused on qualifying general capabilities and identifying issues when the devices are operated under more realistic use cases rather than providing repeatable quantities for comparisons. Figure 6 shows the $\triangle \mathrm{HPRE}_{68}$ (calculated using the 2 min location data record) for each of the measurement locations in the field test during the first test run with the Google Services locator. From the figure it can be observed that locations that were sampled near each other on the same plot have similar errors. This represents points that were sampled close to each other in time, and the similar error level is consistent with the random walk nature of the errors noticed for the "gps" and Google Services locators.

Figure 7 shows how the $\Delta \mathrm{HPRE}_{68}$ varied at each location during the field testing. During the field test, each location

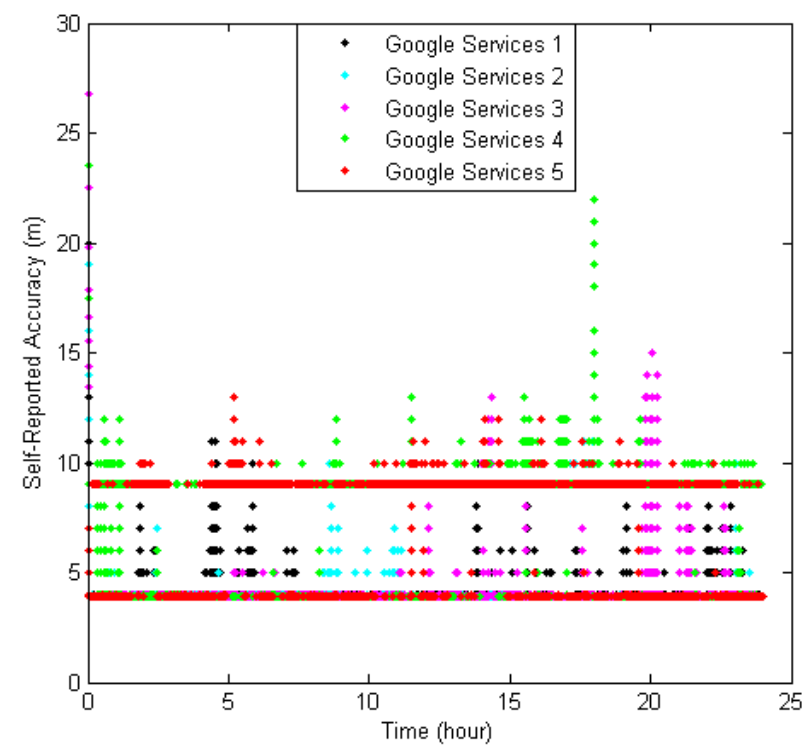

Figure 5. Self-Reported Accuracy of the Google Services locators over the 24-h test period. The tests with Google Services 1 and Google Service 2 each had one reported accuracy that was between 90 and $100 \mathrm{~m}$ which was not plotted. was assigned a number and the testing progressed in order of these assigned values. As inspection of these figures reveals, there was no appreciable pattern with certain locations having higher or lower errors across multiple test runs. Locations with particularly high or low errors in one test did not maintain those error levels in other tests.

The data from each run with each location service has been summarized in table 2. For most parameters (average $\triangle \mathrm{HPRE}_{68}$ of all 88 locations, standard deviation of $\triangle \mathrm{HPRE}_{68}$ between locations, maximum $\triangle \mathrm{HPRE}_{68}$, and median $\triangle \mathrm{HPRE}_{68}$ ) both location services have similar values; however, the "gps" location service tends to be slightly more accurate (lower $\triangle \mathrm{HPRE}_{68}$ ). This observation was confirmed at a significance level of 0.003 by an ANOVA and T-Test in which all of the 264 ( 88 locations in 3 runs) samples for each location service were grouped for comparison between services. The field test did not show the many times higher error for the Google Services locator compared to the "gps" locator that was noticed in the ION 101 testing.

The SRA was very stable in these tests with a nearly constant $3.0 \mathrm{~m}$ ("gps") or $3.9 \mathrm{~m}$ (Google Services) value. Although in 5 of the 6 tests, SRA was smaller than $\triangle$ HPRE $_{68}$, this difference was never more than $1 \mathrm{~m}$. Based on this test, when using these devices for location marking in fields, one would generally expect the tagged location to be within 3 to $5 \mathrm{~m}$ of the true location although some measurements would have higher errors as indicated by the maximum $\triangle \mathrm{HPRE}_{68}$ column. While this is not accurate enough to mark individual rows in row crops, it could be used to identify a particular implement pass with larger implements.

A Tukey HSD statistical test confirmed differences in the mean value for $\triangle \mathrm{HPRE}_{68}$ between some test runs. Table 2 displays which test runs belong to which homogeneous subset through the use of group letters with ' $A$ ' being the most accurate to ' $\mathrm{C}$ ' being the least. The data from the individual test runs in the field confirm that there is variability between each session of using location services. Users should be aware that highly accurate results obtained during one use of location services might not be repeated on another use.

Several applications are available that allow users to calculate the area of regions using their mobile device. The error of this area calculation is related to the total area of the region, its geometry (number and location of vertices) and the error of individual corner measurements. Therefore, it is not a simple matter to express the effect of the error of point measurements on the error of an area which they create. To investigate the use of these services for area determination, the location data recorded during the field testing were used to estimate the areas of 17 rectangular plots. Each one was approximately $100 \times 14 \mathrm{~m}$ or 0.14 ha. Table 3 presents a summary of the errors in areas obtained using each location service in each of three repetitions. Since the positional error of the plots' corners does not follow a regular pattern, the error in area for every plot and consequently for each test with each location service does not either. The maximum area error was $16 \%$ and this was obtained during the third test run with the "gps" locator; however, during every test, at least one plot out of the 17 total plots had an area estimate that was incorrect by more than $10 \%$. 


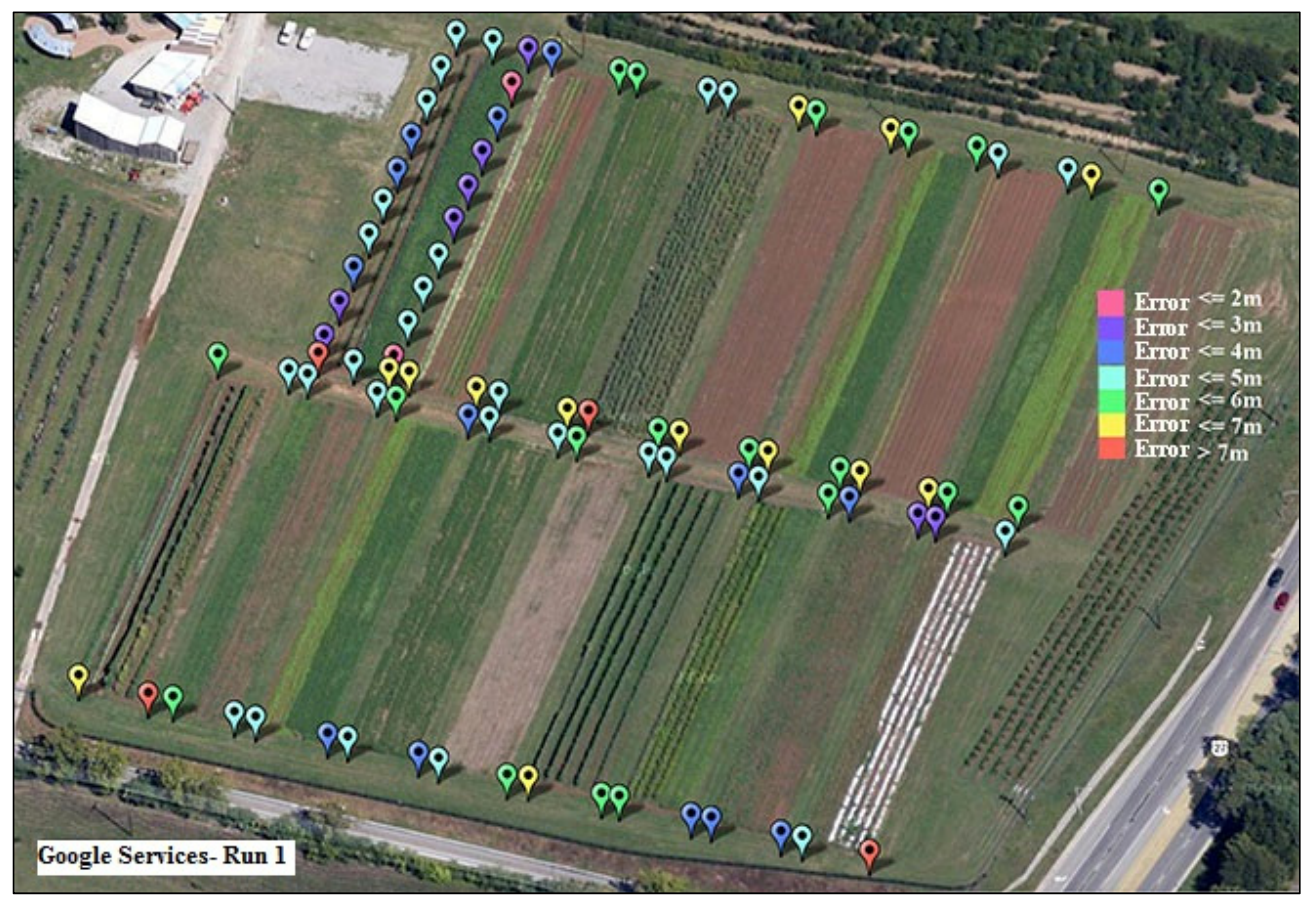

Figure 6. The error, by color, for each location for the first run of Google Services locator.
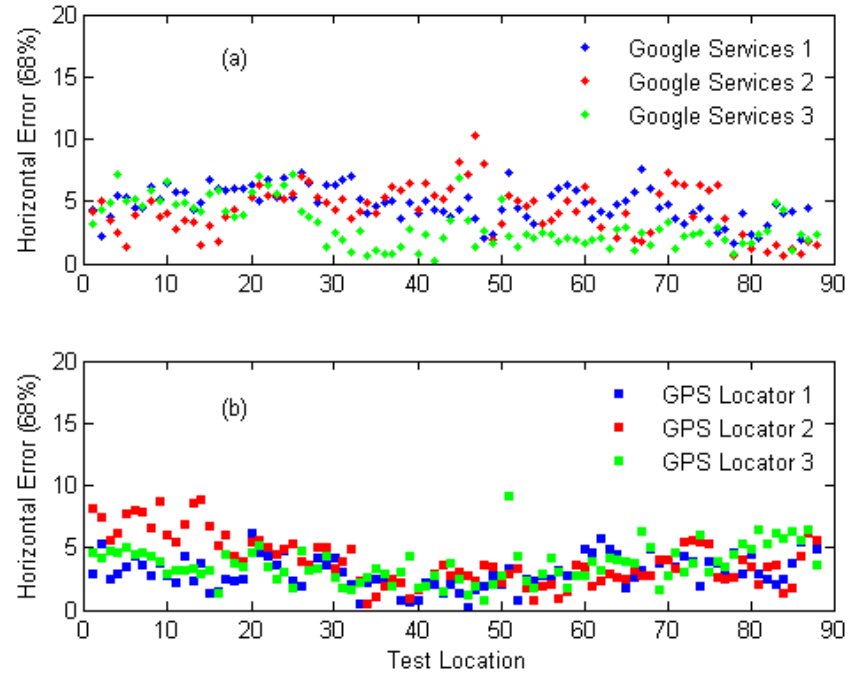

Figure 7. Horizontal error at each location during the field test with (a) Google Services locator and (b) "gps" locator.

The tests conducted in this project reveal some important differences in the location services that are available on contemporary smartphone and tablet devices. Most notably, the newer Google Services location service did not always pro- vide an appropriate value for SRA. In static testing, the difference between $\triangle \mathrm{HPRE}_{68}$ and SRA could be quite large; however, in field testing, the difference was never more than $1 \mathrm{~m}$. In both sets of tests, the standard "gps" locator provided SRA values and operated as expected for an uncorrected GNSS system. It was also the most accurate and consistent service in these tests. The "network" locator had higher SRA, higher $\triangle \mathrm{HPRE}_{68}$ and did not exhibit the random walk pattern seen with the other location services. It also did not operate in the field. All of these findings will be useful for the conscientious developer creating new apps for precision agriculture.

In higher level locating services, the location provider can suddenly change from one like GPS with a random walk to one without - like the network provider - depending on relative accuracies and update rates. This was illustrated in this project by the apparent switching from "network" to "gps" locators as the GPS system warmed up while running the Google Services locator. Unfortunately, within the app, there is no indication that this change has occurred. The only feedback provided from the device to the app was the SRA which this testing showed did not always align with the actual error levels. However, although SRA cannot be completely trusted, it did provide some feedback on error levels as SRAs for "gps" were less than those for Google Services which

Table 2. Summary of the field testing for both location services

\begin{tabular}{lccccc}
\hline \multicolumn{1}{c}{ Run No. } & $\begin{array}{c}\text { Average } \Delta \text { HPRE }_{68} \\
(\mathrm{~m})^{[\mathrm{a}]}\end{array}$ & $\begin{array}{c}\text { Standard Deviation } \\
(\mathrm{m})\end{array}$ & $\begin{array}{c}\text { Maximum } \Delta \text { HPRE }_{68} \\
(\mathrm{~m})\end{array}$ & $\begin{array}{c}\text { Median } \Delta \text { HPRE }_{68} \\
(\mathrm{~m})\end{array}$ & $\begin{array}{c}\text { Average Self-Reported } \\
\text { Error }(\mathrm{m})\end{array}$ \\
\hline "gps" Locator 1 & $3.06 \mathrm{~A}$ & 1.31 & 6.38 & 2.85 & 3.01 \\
"gps" Locator 2 & $3.98 \mathrm{~B}$ & 2.02 & 8.85 & 3.56 & 3.00 \\
"gps" Locator 3 & $3.63 \mathrm{AB}$ & 1.46 & 9.2 & 3.47 & 3.02 \\
Google Services 1 & $4.74 \mathrm{C}$ & 1.36 & 7.52 & 4.72 & 3.90 \\
Google Services 2 & $4.25 \mathrm{BC}$ & 1.96 & 10.34 & 4.26 & 3.90 \\
Google Services 3 & $3.09 \mathrm{~A}$ & 1.79 & 7.2 & 3.47 & 3.90 \\
\hline
\end{tabular}

${ }^{[a]}$ Letters indicate homogeneous subsets at $\alpha=0.05$. 
Table 3. Summary of errors associated with using these location services to measure areas.

\begin{tabular}{|c|c|c|c|c|}
\hline Run No. & $\begin{array}{c}\text { Mean Absolute Area Error } \\
(\%)\end{array}$ & $\begin{array}{c}\text { Std. Deviation of Absolute Error } \\
(\%)\end{array}$ & $\begin{array}{c}\text { Largest Area Error } \\
(\%)\end{array}$ & $\begin{array}{c}\text { Median Area Error } \\
(\%)\end{array}$ \\
\hline "gps" Locator 1 & 4.7 & 3 & 11.74 & -2.46 \\
\hline "gps" Locator 2 & 4.44 & 3.38 & -12 & -0.83 \\
\hline "gps" Locator 3 & 7 & 4.66 & 16 & -3.58 \\
\hline Google Services 1 & 3.65 & 3.2 & 12.2 & -0.59 \\
\hline Google Services 2 & 4.2 & 2.56 & -10.2 & -2.59 \\
\hline Google Services 3 & 5.4 & 4.36 & 14 & 2.73 \\
\hline
\end{tabular}

were less those for the "network" locator - the same order observed for measured accuracy levels. The reported SRA will depend on the relative accuracies of the different services at the time of the switch. In general, with these higher level services it is impossible to determine when error patterns switch from the random walk to a more chaotic pattern. Developers accustomed to the characteristics of GNSS must be aware these devices do not conform to their standard mental picture of a locating device.

\section{CONCLUSiOnS}

Engineers working in precision agriculture have become accustomed to the characteristics of GNSS with its random walk pattern. However, as this project revealed, assumptions such as the existence of the random walk pattern are not always justified with these devices. Engineers and app programmers who decide or are forced to use the higher level location services should also be aware that the source, and thus characteristics, of the location information could change without notice. As more applications are developed and more end-users begin to utilize the location services within these devices, Extension professionals and others working in precision agriculture outreach efforts need to ensure that these farmers understand the differences between the location information provided by these devices and those provided by their traditional GNSS receivers. In their current state, these devices seem best used for low accuracy general knowledge location information such as marking rocks or sink holes to make them easier to find during later remediation efforts. For these applications, the observed error of 3 to $5 \mathrm{~m}$ would still get the operator close enough to identify the marked feature. However, they are less suited for operational location information, such as defining the borders of small wet regions in terrace channels to enable automatic plant variety switching in multi-hybrid planters. For such operational uses, the uncertainty in accuracy or error characteristics make the system dangerously susceptible to producing improper actions. In many instances, the observed 3 to $5 \mathrm{~m}$ error in location would be equal to the width of the wet spot in a terrace channel, so the entire location could easily be missed. Even in larger regions, such as the tested 0.14 ha plots, area was measured incorrectly with an error of over $10 \%$ in at least one out of the 17 plots. A $10 \%$ error level would represent a significant area to which an input was misapplied.

Agriculture is an industry in which location is very important and relying on services created for general purpose apps (however strongly recommended or popular) may not be the best solution. App developers should test their application in likely use cases, and users should verify the ability to operate at necessary accuracy levels. As illustrated by this project, a single device can operate in different modes with very little feedback to the end-user. App developers should consider providing the user information on the accuracy level of the reported location estimate and greater transparency on how the location estimate was produced. The accuracy estimate may be incorrect as demonstrated with the results from the ION 101 testing with Google Services, but it at least followed the correct trend for the different services. End users will likely start demanding this type of information as these location-based services become more widespread in valuable agricultural decision making processes. App developers who are more candid in presenting this information will likely find better reception among producers adopting their apps and services.

\section{ACKNOWLEDGEMENTS}

This work is supported by the USDA National Institute of Food and Agriculture (NIFA) Hatch Multistate project under 1001110.

\section{REFERENCES}

Apple, Inc. (2015a). CLLocation class reference. Retrieved from https://developer.apple.com/reference/corelocation/cllocation

Apple, Inc. (2015b). Core location constants reference. Retrieved from

https://developer.apple.com/reference/corelocation/1612506core_location_constants

Apple, Inc. $(201 \overline{5 c})$. Getting the user's location. Retrieved from https://developer.apple.com/library/content/documentation/User Experience/Conceptual/LocationAwarenessPG/CoreLocation/C oreLocation.html

Beaudette, D. (2011). SoilWeb: California soil resource lab. Retrieved from

https://play.google.com/store/apps/details?id=casoilresource.app s.soilweb\&hl=en

Doering, C. (2013). Farmers growing comfortable with mobile devices. USA Today. Retrieved from

http://www.usatoday.com/story/news/nation/2013/03/03/farming -technology-ipad-apps/1959139/

Drill, S. L. (2012). Mobile applications for extension. J. Extension (on-line), 50(5), Article 5TOT1.

Dupont Pioneer. (2013). Pioneer Field360" ${ }^{\mathrm{TM}}$ Plantability. Retrieved from

https://play.google.com/store/apps/details?id=com.pioneer.plant ability\&hl=en

Dvorak, J. S., Franke-Dvorak, T. C., \& Price, R. R. (2012). Apps: An innovative way to share extension knowledge. J. Extension (on-line), 50(6), 6IAW2. 
Google. (2015a). Android API reference: Location. Retrieved from https://developer.android.com/reference/android/location/Locati on.html

Google. (2015b). Making your app location-aware. Retrieved from https://developer.android.com/training/location/index.html

GPS NAVSTAR. (1995). Global positioning system standard positioning service signal specification.

Guenthner, J. F., \& Swan, B. G. (2011). Extension learners' use of electronic technology. J. Extension, 49(1), 1FEA2.

McCullough, P. E., Waltz Jr, F. C., Hudson, W., \& MartinezEspinoza, A. D. (2011). Turfgrass management at your fingertips: Information delivered through "smart" phone technology. J. Extension (on-line), 49(3), 1-6.

National Corn Growers Association. (2013). IRM refuge calculator. National Corn Growers Assoc. Retrieved from https://play.google.com/store/apps/details?id=com.ncga.irm.refu ge.calculator\&hl=en

Open Ag ToolKit. (2014a). Field work - OpenATK. Open Ag

ToolKit. Retrieved from https://play.google.com/store/apps/details?id=com.openatk.field work

Open Ag ToolKit. (2014b). Rock - OpenATK. Open Ag ToolKit. Retrieved from https://play.google.com/store/apps/details?id=com.openatk.rock app\&hl=en

Precision Laboratories, LLC. (2014). Mix tank - Tank mixing Ag App. Precision Laboratories, LLC. Retrieved from https://play.google.com/store/apps/details?id=com.lht.precisionl abs.mixtank\&hl=en
Qualcomm Technologies. (2014). Snapdragon S4, S3, S2, and S1. Retrieved from https://www.qualcomm.com/products/snapdragon/processors/s4 -s1

The Institute of Navigation. (1997). ION STD 101, Recommended test procedures for GPS receivers (Revision $\mathrm{C}$ ed.). Manassas, VA.

Trimble Navigation. (2014). Connected farm scout. Trimble Navigation. Retrieved from https://play.google.com/store/apps/details?id=com.trimble.agma ntra\&hl=en

Watershed Management Apps Center. (2013). Watershed delineation - WMAC. Watershed Management Apps Center. Retrieved from https://play.google.com/store/apps/details?id=org.waterapps.wat ershed

Watershed Management Apps Center. (2014). Water plane WMAC. Watershed Management Apps Center. Retrieved from https://play.google.com/store/apps/details?id=com.waterapps.wa terplane

Welte, J., Ault, A., Bowman, C., Layton, A., Noel, S., Krogmeier, J., \& Buckmaster, D. (2013a). Autogenic mobile computing technologies in agriculture: Applications and sensor networking for smart phones and tablets. EFITA2013.

Welte, J. T., Ault, A. C., Bowman, C., Ellis, S., Buckmaster, D. R., Ess, D., \& Krogmeier, J. V. (2013b). An approach to farm management information systems using task-specific, collaborative mobile apps and cloud storage services. ASABE Paper No. 131579954. St. Joseph, MI: ASABE. http://dx.doi.org/10.13031/aim.20131579954 